\title{
A Low-Cost Miniature Electrohydrostatic Actuator
}

\author{
Travis Wiens ${ }^{1^{*}}$, and Brendan Deibert ${ }^{1}$
}

1 Department of Mechanical Engineering, University of Saskatchewan

* Correspondence: t.wiens@usask.ca

\begin{abstract}
This paper presents a low-cost, small-scale, electrohydrostatic actuator (EHA). This actuator leverages low-cost mass-produced hydraulic components from the radio-controlled model industry, combined with a novel 3D printed valve. The system is capable of relatively high bandwidth operation, with much higher power- and force-density than comparable electrical actuators. This paper presents a dynamic system model, investigating the range of stability.
\end{abstract}

Keywords: hydraulics; fluid power; electrohydrostatic actuator; EHA

\section{Introduction}

There has been much recent research in the field of pump-controlled hydraulic actuators, also known as electrohydrostatic actuators (EHA) (see [1] for a recent review). These actuators promise higher efficiencies than valve-controlled actuators (with their associated losses across throttling valves). They can also offer advantages from a control point of view due to their linearity and load insensitivity. One configuration uses a variable speed motor coupled to a fixed displacement pump (often a gear pump). If this is used to drive a single-rod cylinder, some facility for balancing the asymmetric flows must be included [2]-[8].

These actuators have commercial acceptance in the high power range, including current use for flight control surfaces on Airbus A380 aircraft [9]. Commercial EHA units are available from a number of manufacturers [10].

In the small actuator range (i.e. displacements on the order of $50 \mathrm{~mm}$ and force capacity on the order of $50 \mathrm{~N}$ ) electrical screw driven actuators are common [11]. How ever, these actuators suffer from low force and power density and high friction.

In recent years, small scale hydraulic systems have become available, driven by radio-controlled model equipment (some would say "toys"). These systems feature small hydraulic cylinders driven by gear pumps driven by variable speed brushless DC or permanent magnet motors. The system is usually valve controlled with the pump running at constant speed over a relief valve, resulting in an inefficient and load-sensitive circuit. This paper presents the application of these low-cost components in an EHA configuration. Previously, the lack of a suitable flow balancing system made these systems economically impractical, so the major contribution of this project is a low-cost flowbalancing valve. 


\section{Materials and Methods}

\subsection{System Description}

The prototype system is shown in Figure 1 and schematic in Figure 3. The fixed displacement gear pump is driven by a variable speed electric motor, in this case a permanent magnet motor (commonly referred to as brushless DC, or BLDC). The pump and motor were purchased as a matched set, with a rated pressure of $4.5 \mathrm{MPa}$. For research purposes we drove the motor using an ODrive $24 \mathrm{~V}$ motor controller [12], but this could be easily replaced with a low-cost BLDC electronic speed control(ESC) unit.

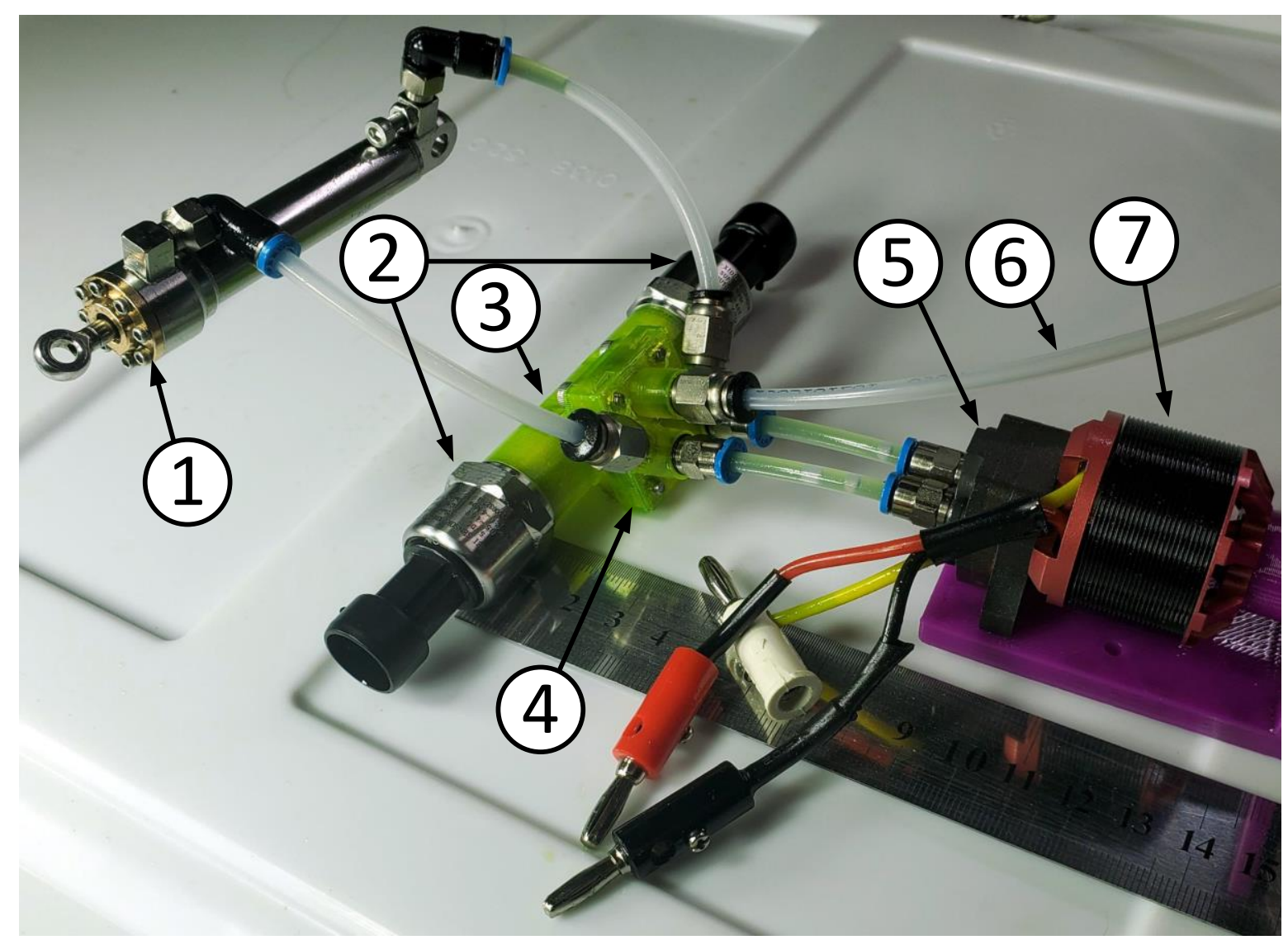

Figure 1. Photos of system, including (1) hydraulic cylinder, (2) pressure transducers, (3) 3D printed valve, (4) mounting plate, (5) pump, (6) charge pump line, and (7) motor. A cm ruler is included for scale. (Note that this photow as taken before bleeding air from the system.)

A commercially purchased hydraulic cylinder was used as the actuator, with $10 \mathrm{~mm}$ bore diameter, $4 \mathrm{~mm}$ rod diameter and $50 \mathrm{~mm}$ stroke. This cylinder was provided without a technical datasheet, but appears to have a hard, low-friction piston seal (perhaps polytetrafluoroethylene, PTFE) and has a soft elastomeric rod seal, likely nitrile rubber.

The single asymmetric hydraulic cylinder's unbalanced flow is handled by the inverse shuttle valve, shown in Figure 2. This valve connects the cylinder port with the low er pressure to the low pressure supply. For testing purposes, this low pressure was supplied by an external pump, but it is believed that it would be possible for this to be replaced $w$ ith a reservoir or accumulator [13]. The valve casing was 3D printed from polyethylene terephthalate glycol-modified (PETG) using a Prusa i3 $\mathrm{mk} 3$ fused filament printer, at a layer height of $0.10 \mathrm{~mm}$ and $100 \%$ infill. The casing was produced with optional pressure transducers forming end caps, threaded into printed threads. The captured spool was printed in place, a layout that cannot be realized without using additive manufacturing. The authors believe this is the first hydraulic valve to require neither assembly nor finish machining. 
This design uses two connected hemispherical poppets which seat into conical seats. The hemispherical shape allows for good sealing even with angular misalignment of the unguided poppet. Once designed, the cost to produce this valve is nearly negligible, with a material cost of less than US\$ 1 and requiring less than 4 hours of unattended printing time. For those without access to a 3D printer, numerous commercial enterprises can produce this part at minimal cost. We received commercial quotes for single quantities as low as US $\$ 13$ plus shipping and less than US $\$ 2$ in bulk quantities.

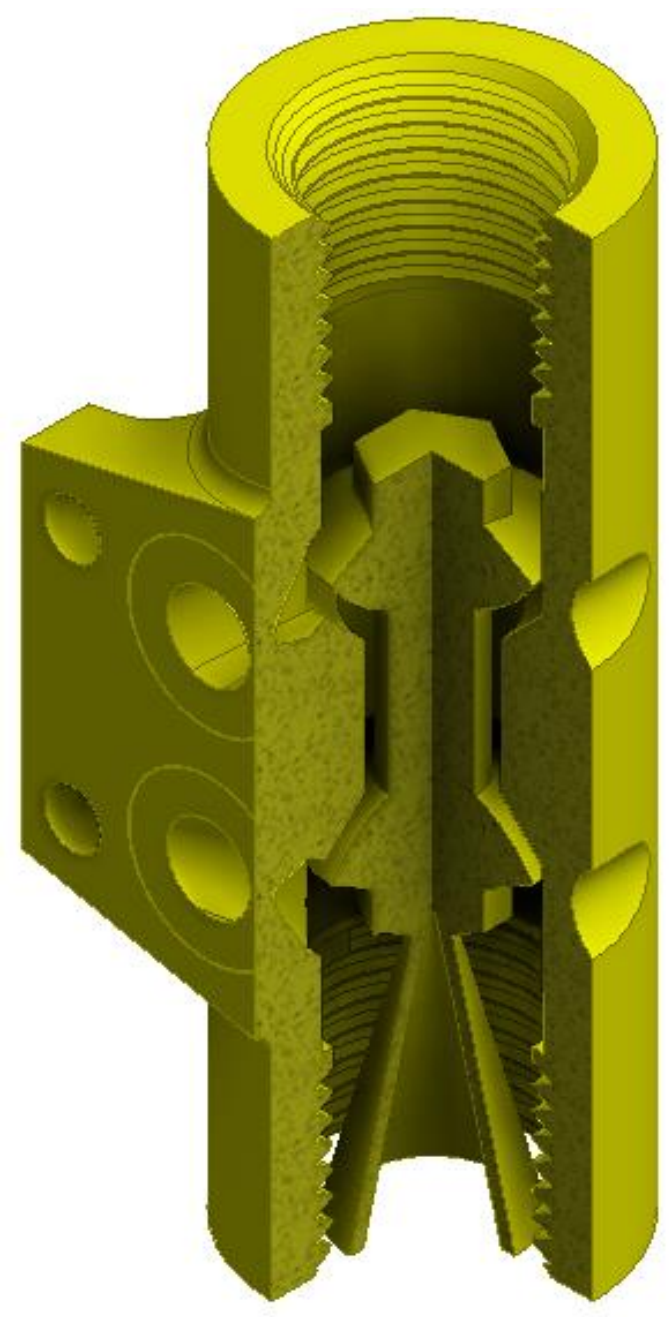

Figure 2. Cutaway view of the 3D printed PETG valve. The conical structure at the bottom is a support required during printing and is removed by gripping the hexagonal shape on the top of the spool and twisting. For both valves, pressures $P_{A}$ and $P_{B}$ are connected via passageways through the casing (not clearly visible here) to the top and bottom chambers and the charge pressure $P_{C}$ is connected to the center of the casing between the two hemispherical sealing surfaces. 3D printed thre ads at the top and bottom accommodate pressure transducers for the prototype valve, which may be eliminated if not required.

All connecting lines are nylon tubing, rated for $4 \mathrm{MPa}$, which sets the safe w orking pressure of the system. Rather than physical relief valves to enforce this pressure limit, we used the measured pressure to limit the pump velocity for this prototype. This system is not entirely reliable, so rupture discs or other weak points could be included in a production version to ensure safety. Alternately, the motor current could be limited in order to limit pressure if pressure measurement was not required. 
A previous paper [13] evaluated the steady state performance of the system and found it to have a very high specific force and pow er when compared to electrical actuators.

\subsection{Dynamic Model}

This section presents a dynamic model for the system, using nomenclature shown in Figure 3.

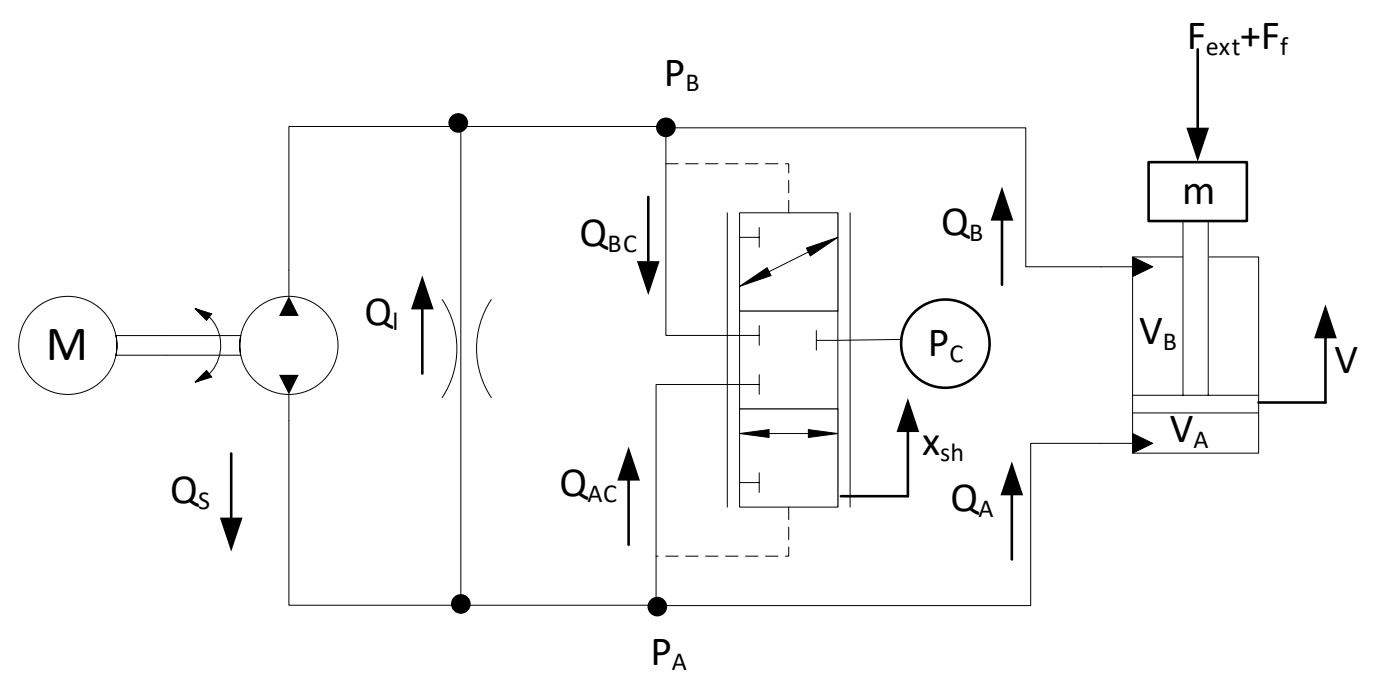

Figure 3. System schematic and nomenclature

Starting at the load, a force balance on the piston and attached mass gives

$$
m \frac{d V}{d t}=P_{A} A_{A}-P_{B} A_{B}-F_{e x t}-F_{f}
$$

where $A_{A}$ and $A_{B}$ are the piston areas on the head and rodend, $F_{\text {ext }}$ is the externally applied force, $V$ is the actuator velocity and, following an equation modified from [14], the effective friction force is given by

$$
F_{f}=\left(F_{c}+K_{P B} \mu P_{B}\right) \tanh \left(\frac{V}{V_{f}}\right)+K_{B} \mu V
$$

where $F_{c}$ is the Coulomb Friction, $\mu$ is the dynamic viscosity, $K_{P B}$ is a pressure-dependent friction term, $K_{B}$ is a viscous damping term and $V_{f}$ is a scale for "small" velocities (this tanh term is used to avoid numerical instability around zero velocity). Fluid friction in lines and fittings is also lumped into $K_{B}$ (which should have a small effect). We investigated including a turbulent friction term (proportional to $V^{2}$ ) but found its value to be statistically indistinguishable from zero in experimental tests. Likewise, a $P_{A}$ friction term $w$ as considered but $w$ as also indistinguishable from zero, likely due to the hard piston seal, as compared to the deformable elastomeric rod gland seal.

Assuming constant effective bulk modulus, $\beta$, in the fluid and containing passageways, continuity requires

$$
\begin{gathered}
\frac{V_{A}}{\beta} \frac{d P_{A}}{d t}=Q_{s}-Q_{l}-Q_{A C}-V A_{A} \\
\frac{V_{B}}{\beta} \frac{d P_{B}}{d t}=-Q_{s}+Q_{l}-Q_{B C}+V A_{B}
\end{gathered}
$$

where $V_{A}$ and $V_{B}$ are the effective compliant volumes (including valve bodies, lines and piston chambers).

The shuttle valve spool is assumed to have laminar friction and flow forces are neglected, giving a force balance of 


$$
m_{s h} \frac{d^{2} x_{s h}}{d t^{2}}=\left(P_{A}-P_{B}\right) A_{s h}-B_{s h} \frac{d x_{s h}}{d t}
$$

where $m_{s h}$ is the spool's mass, $A_{s h}$ is the symmetrical piston area, and $B_{s h}$ is the damping coefficient. The minimum and maximum displacement are limited by $x_{\text {shmin }}$ and $x_{\text {shmax }}$.

This model lumps all internal leakage (i.e. pump, valve, and cylinder) into $Q_{l}$ and all external leakage and valve flow into $Q_{A C}$ and $Q_{B C}$. Laminar internal leakage is given by

$$
Q_{l}=\frac{P_{A}-P_{B}}{\mathrm{R}_{1}}
$$

where $R_{l}$ is the leakage resistance. The external leakage and valve flows are given by

$$
\begin{gathered}
Q_{A C}=\frac{P_{A}-P_{C}}{\mathrm{R}_{\mathrm{AC}}} \\
Q_{B C}=\frac{P_{B}-P_{C}}{\mathrm{R}_{\mathrm{BC}}}
\end{gathered}
$$

where $R_{A C}$ and $R_{B C}$ are the resistances, with conductances linearly varying with spool position

$$
\begin{aligned}
& R_{A C}^{-1}=R_{A C l}^{-1}+R_{A C v}^{-1} \frac{x_{\text {shmax }}-x}{x_{\text {shmax }}-x_{\text {shmin }}} \\
& R_{B C}^{-1}=R_{B C l}^{-1}+R_{B C v}^{-1} \frac{x-x_{\text {shmin }}}{x_{\text {shmax }}-x_{\text {shmin }}}
\end{aligned}
$$

where $R_{A C l}$ and $R_{B C l}$ are the leakage resistances with the valve closed, and $R_{A C v}$ and $R_{B C v}$ are the resistances when fully open (including both valve orifices and passagew ay resistances). While the orifices are likely turbulent at partial opening, the fast-responding valve spends the vast majority of its time at either extreme where the resistance is either dominated by laminar leakage flow or laminar pipe flow. The intermediate resistances are largely included as a convenience for the numerical solver and have little effect on the system dynamics.

Table 1 shows parameters used for the simulation study, some of which were experimentally estimated in a previous work [13]. 
Table 1. Model Parameters.

\begin{tabular}{cc}
\hline Parameter & Value \\
\hline Head End Piston area $A_{A}$ & $78.5 \mathrm{~mm}^{2}$ \\
Rod End Piston Area, $A_{B}$ & $66.0 \mathrm{~mm}^{2}$ \\
Fluid Viscosity, $\mu$ & $28.3 \mathrm{cP}$ \\
Fluid Bulk Modulus, $\beta$ & $1.0 \mathrm{GPa}$ \\
Load Friction Viscous Coefficient $K_{B}$ & $2.50 \mathrm{e} 4 \mathrm{~N} /(\mathrm{m} / \mathrm{s}) /(\mathrm{Pa} \mathrm{s})$ \\
Load Coulomb Friction, $F_{C}$ & $3.41 \mathrm{~N}$ \\
Load Pressure Friction Coefficient, $K_{P B}$ & $5.27 \mathrm{e}-6 \mathrm{~N} /(\mathrm{m} / \mathrm{s}) / \mathrm{Pa}$ \\
Friction reference velocity, $V_{f}$ & $0.01 \mathrm{~mm} / \mathrm{s}$ \\
Load mass, $m$ & $1.25 \mathrm{~kg}$ \\
Internal Leakage Resistance $R_{l}$ & $1.23 \mathrm{e} 12 \mathrm{~Pa} /(\mathrm{m} 3 / \mathrm{s})$ \\
External Leakage Resistance $R_{A C l}$ & $6.83 \mathrm{e} 14 \mathrm{~Pa} /(\mathrm{m} 3 / \mathrm{s})$ \\
External Leakage Resistance $R_{B C l}$ & $2.41 \mathrm{e} 12 \mathrm{~Pa} /(\mathrm{m} 3 / \mathrm{s})$ \\
Open Valve Resistance $R_{A C}$ & $1.11 \mathrm{e} 11 \mathrm{~Pa} /(\mathrm{m} 3 / \mathrm{s})$ \\
Open Valve Resistance $R_{B C}$ & $5.29 \mathrm{e} 9 \mathrm{~Pa} /(\mathrm{m} 3 / \mathrm{s})$ \\
ShuttleSpool Piston Area, $A_{s h}$ & $50.3 \mathrm{~mm}{ }^{2}$ \\
ShuttleSpool Damping, $D_{s h}$ & $12.2 \mathrm{~N} /(\mathrm{m} / \mathrm{s})$ \\
ShuttleSpool mass, $m_{s h}$ & $1.2 \mathrm{~g}$ \\
Maximum spool displacement, $x_{\text {shmax }}$ & $2 \mathrm{~mm}$ \\
Minimum spool displacement, $x_{\text {shmin }}$ & $-2 \mathrm{~mm}$ \\
$P_{A}$ compressible volume, $V_{A}$ & $2.55 \mathrm{~mL}$ \\
$P_{B}$ compressible volume, $V_{B}$ & $2.24 \mathrm{~mL}$ \\
Charge Pump Pressure, $P_{C}$ & $250 \mathrm{kPa}$ \\
Main pump maximum flow,,$Q_{s m a x}$ & $0.7 \mathrm{~L} / \mathrm{min}$ \\
\hline & \\
&
\end{tabular}

\subsection{Controller}

This section presents an open-loop velocity controller for the system. This is intended to be a minimum viable controller, intended to provide an indication of the stability and controllability of the system, rather than an optimized controller that would actually be used in practice.

First, the controller estimates the valve spool state, either in mode $1\left(P_{A}>P_{B}\right)$ or mode $2\left(P_{B}>\right.$ $P_{A}$ ). In the ideal case this is simply

$$
\text { mode }= \begin{cases}1 & \text { if } P_{A}>P_{B} \\ 2 & \text { otherwise }\end{cases}
$$

More complex realistic controllers would apply filters and/or hysteresis to prevent spurious mode switching due to measurement noise.

Based on the mode, the flow required to achieve the desired velocity, $V_{r e f}$, is calculated, assuming no leakage:

$$
Q_{s}=\left\{\begin{array}{lc}
V_{\text {ref }} A_{A} & \text { if mode }=1 \\
V_{\text {ref }} A_{B} & \text { otherwise }
\end{array}\right.
$$

As the leakage is dependent on the measured pressures $P_{A}$ and $P_{B}$, a practical controller could improve steady state accuracy by compensating for this leakage. 


\subsection{Simulation Studies}

The above system of equations was implemented in Matlab Simulink. A input of $V_{\text {ref }}=0$ was applied and the system was allowed to reach steady state. A step in reference velocity was then applied and the actuator velocity and pressures were recorded for a constant load force $F_{\text {ext }}$.

\section{Results}

Figure 4 shows representative step response results for a range of load forces and commanded velocities. Figure 5 show s an example of a limit cycle that can be excited under certain conditions and Figure 6 show s a map of which operating points excite this limit cycle. 


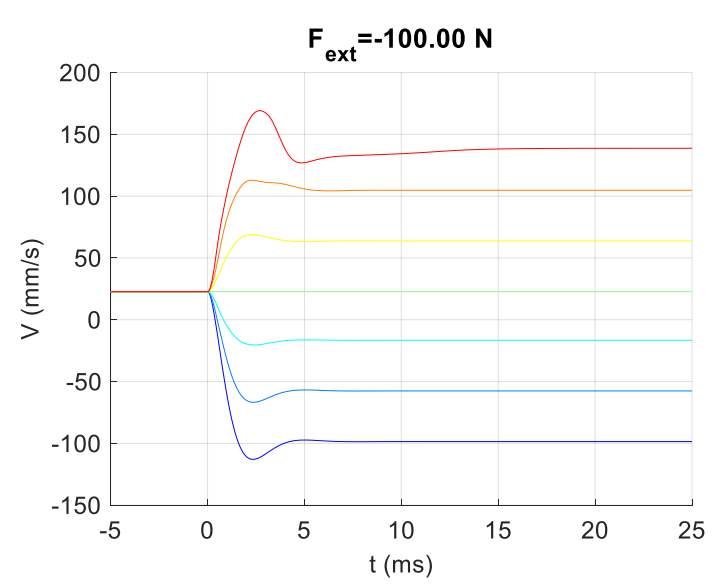

(a)

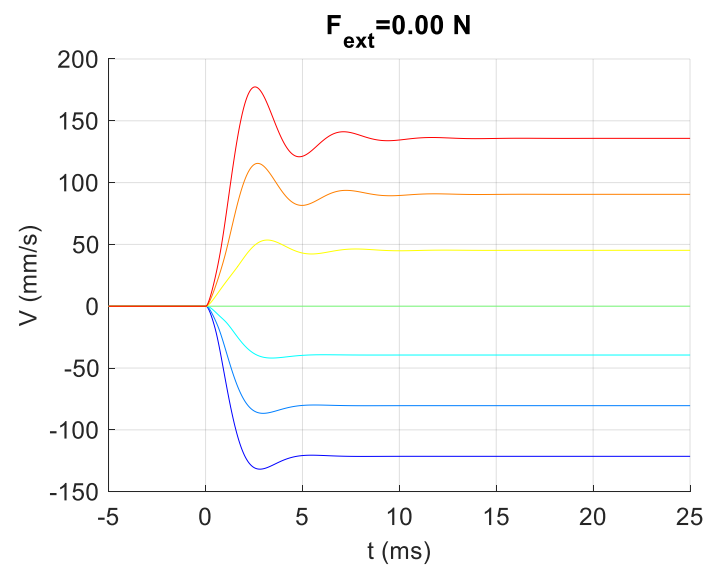

(c)

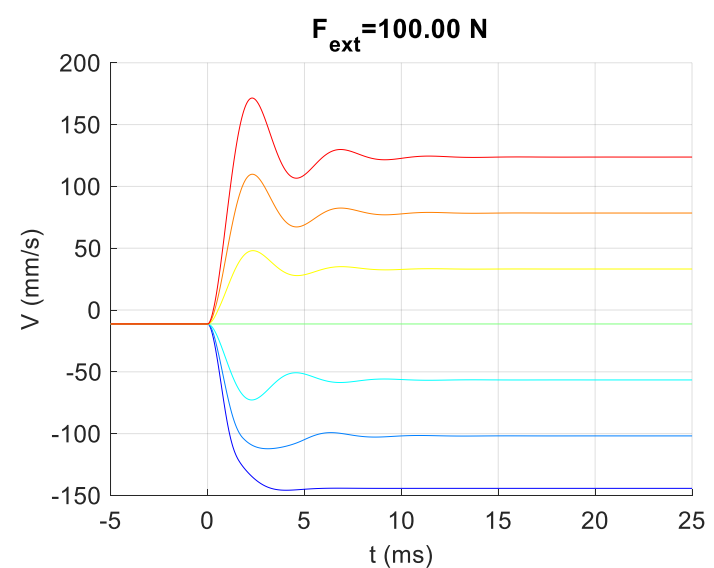

(e)

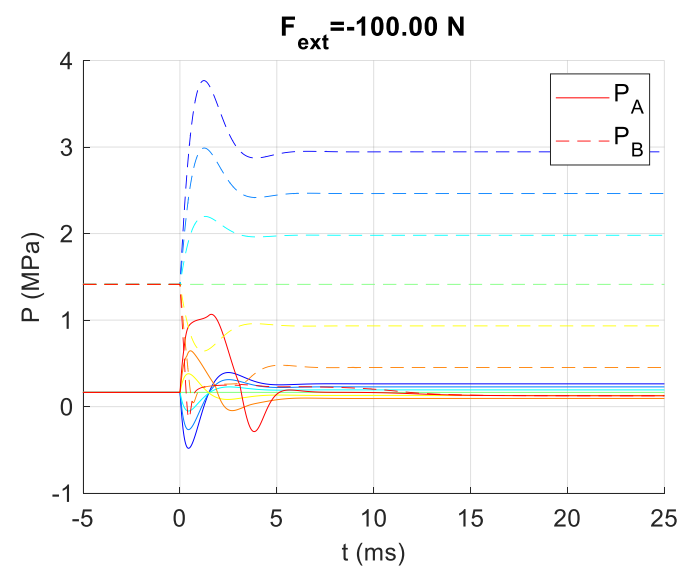

(b)

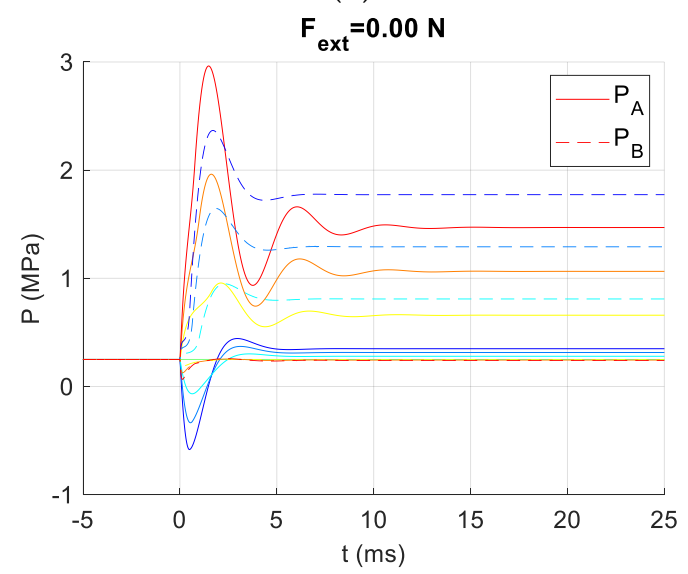

(d)

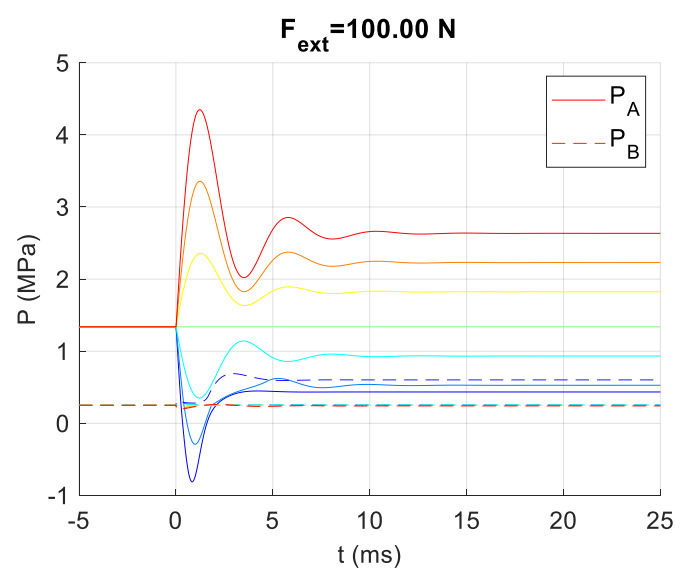

(f)

Figure 4. Example step responses, for a range of external load forces (different rows) and commanded velocities (different colors). Colors represent the same command velocity in each plot. 


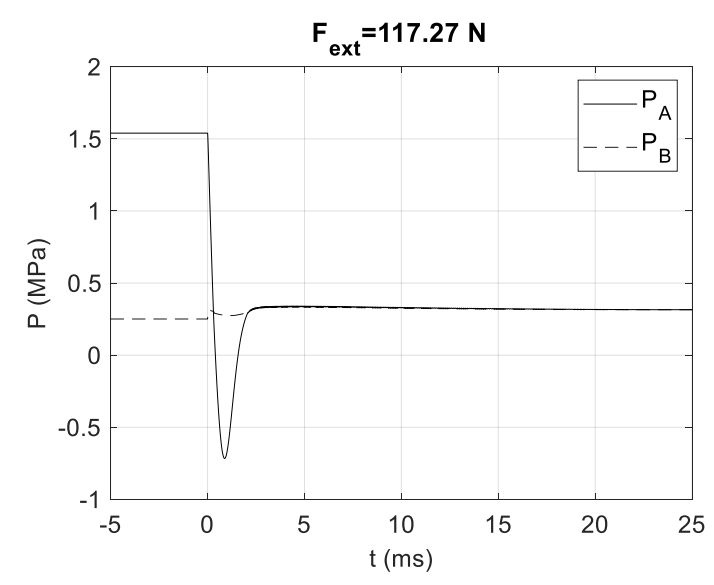

(a)

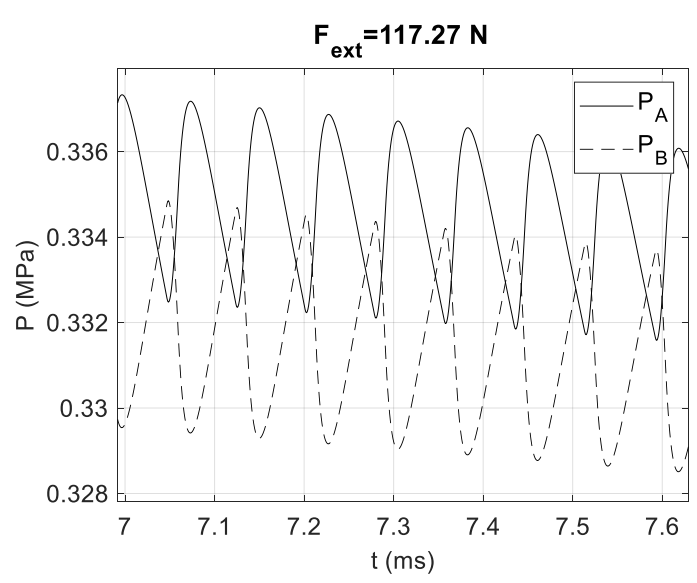

(a)

Figure 5. An example of a pressure limit cycle for $V_{\text {ref }}=-148.5 \mathrm{~mm} / \mathrm{s}$ and $F_{\text {ext }}=117.3 \mathrm{~N}$, enlarged in Frame (b)

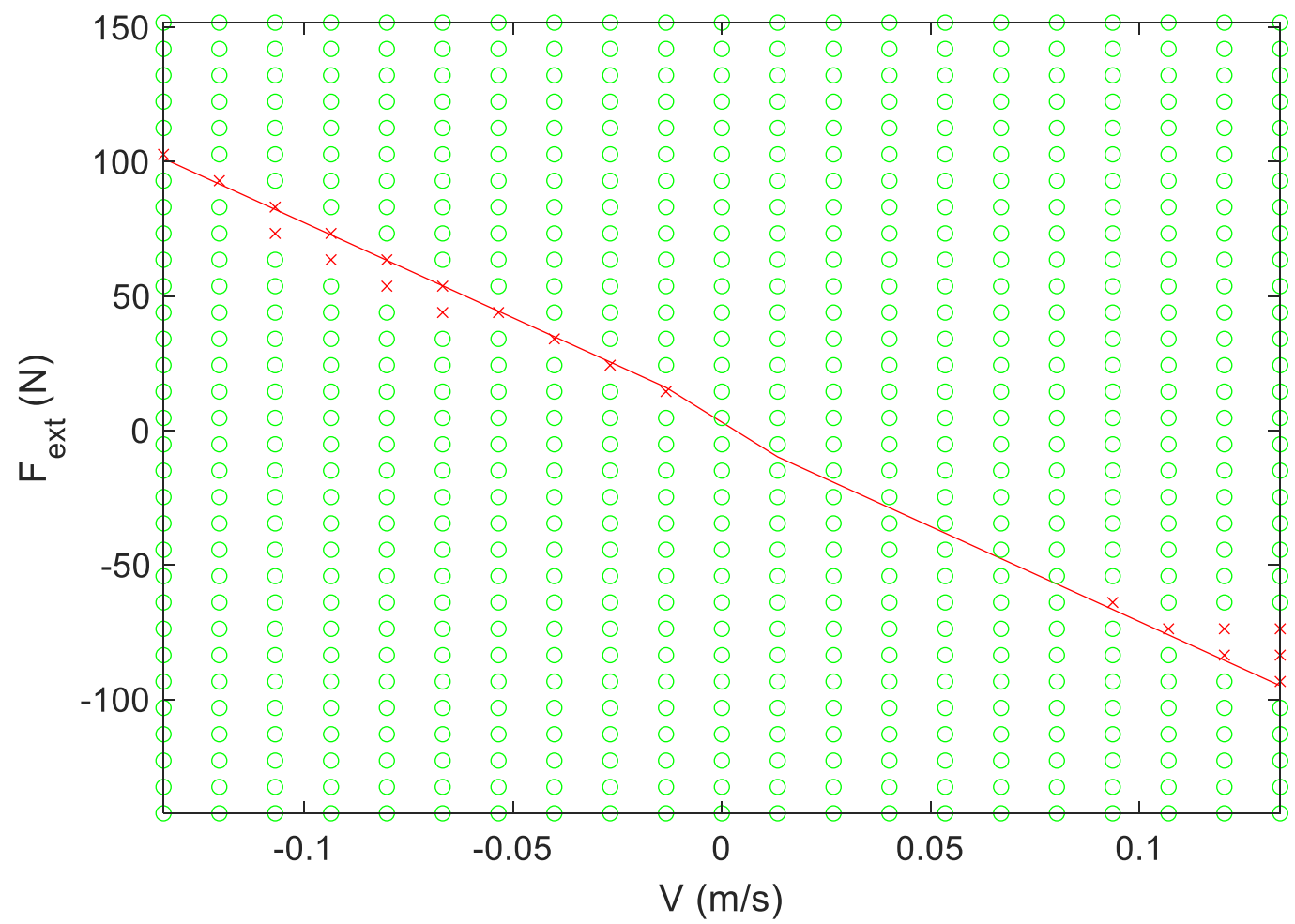

Figure 6. An oscillating pressure limit cycle exists for the points denoted by a red $x$, while no oscillations exist for green circles. The red line denotes the critical load force where $P_{A}=P_{B}$ at equilibrium.

\section{Discussion}

As seen in Figure 4, the dynamic response is generally fast and oscillations settle quickly. The nonlinear nature of the system can be observed as the velocity response's shape changes with operating point, with some responses overdamped, and others showing some overshoot.

How ever, as show $\mathrm{n}$ in Figure 5, it is possible to excite a limit cycle, with the pressure continually oscillating. This instability has been identified in the literature [15]-[17] as being related to modeswitching of the shuttle valve spool around a critical external force when $P_{A}=P_{B}$. In [15], it is stated that the size of the unstable region around the critical force is related to the shuttle spool centering spring and orifice geometry. Following this theory, eliminating the spring (as in this paper) would 
represent an infinitesimal unstable zone. How ever, we still observe a small unstable zone, as shown in Figure 6. Luckily, this zone is very small and it may be possible to mitigate the effects by adding leakage or pressure feedback [17].

\section{Conclusions}

This paper presents a dynamic model of a single-rod electrohydrostatic actuator with a novel 3D-printed shuttlevalve. These dynamic results indicate that a known issue with stability is small with this valve, but is not entirely eliminated. Future work will further develop our understanding of the causes of this limit cycle with the aim of eliminated it. The dynamic model will also be used to optimize system parameters.

Acknowledgments: This research and APC were funded by Natural Sciences and Engineering Re search Council of Canada, grant number 2017-05906. The authors wish to acknowledge Joe Murray of the Lil Giants Construction Co YouTube Channel for the donation of some preliminary equipment while international shipments were delayed during the COVID-19 pandemic.

Author Contributions: Travis Wiens conceived and designed the experiments and model, and analysed the data; Brendan Deibert performed background research. Both contributed to writing the paper.

Conflicts of Interest: The authors decla re no conflict of interest

\section{Abbreviations}

The following abbreviations are used in this manuscript:

EHA: Electrohydrostatic Actuator

\section{References}

[1] S. Ketelsen, D. Padovani, T. O. Andersen, M. K. Ebbesen, and L. Schmidt, “Classification and Review of Pump-Controlled DifferentialCylinder Drives," Energies, vol. 12, no. 7, p. 1293, 2019.

[2] H. E. Merritt, “Hydraulic control systems, 1967,” J. Wiley.

[3] S. Ketelsen, G. Kolks, T. O. Andersen, L. Schmidt, and J. Weber, “Bootstrap reservoir concepts for electrohydraulic compact cylinder drives," 2020.

[4] S. Zhang, T. Minav, and M. Pietola, "Decentralized Hydraulics for Micro Excavator," in Proceedings of 15: th Scandinavian International Conference on Fluid Power, June 7-9, 2017, Linköping, Sweden, 2017, no. 144, pp. 187195.

[5] T. Wiens and D. Bitner, “An efficient, high performance and low-cost energy recovering hydrostatic linear actua tor concept," 2016.

[6] T. Wiens, “An efficient, compact and low-cost DualCylinder Hydrostatic Actuator (DCHA)," International Journal of Fluid Power, vol. 19, no. 2, pp. 80-90, 2018.

[7] P. J. Achten and J. O. Palmberg, "What a difference a hole makes: the commercial value of the Innas hydraulic transformer," in The sixth Scandinavian international conference on fluid power (Tampere, May 26-28 1999, proceedings), 1999, pp. 873-886.

[8] G. K. Costa and N. Sepehri, "Four-quadrant analysis and system design for single-rod hydrostatic actuators," Journal of Dynamic Systems, Measurement, and Control, vol. 141, no. 2, 2019.

[9] C. Adams, “A380: 'More Electric' Aircraft,” Aviation Today, Oct. 01, 2001.

[10] Parker, “Compact Electro-Hydraulic Actuator (EHA),” 2020. Accessed: Nov. 16, 2020. [Online]. Available: https://www.parker.com/Literature/Hydraulic\%20Pump\%20Division/Oildyne\%20EHA/Compact-EHACatalog-HY22-3101E-7-13.pdf.

[11] Actuonix Motion Devices, “Miniature Linear Motion Series-L16.” 2019, Accessed: Oct. 27, 2020. [Online]. Available:https://s3.amazonaws.com/actuonix/Actuonix+L16+Data sheet.pdf. 
[12] Odrive Robotics, “Odrive High Performance Motor Control.” Accessed: Oct. 27, 2020. [Online]. Available: https://odriverobotics.com/.

[13] T. Wiens and B. Deibert, "A Low-cost Miniature Electrohydrostatic Actua tor System," Actutors, vol. Under review.

[14] A. Bonchis, P. I. Corke, and D. C. Rye, "A pressure-based, velocity independent, friction model for asymmetric hydraulic cylinders," in Proceedings 1999 IEEE international conference on robotics and automation (Cat. No.99ch36288c), 1999, vol. 3, pp. 1746-1751.

[15] H. Çalışkan, T. Balkan, and B. E. Platin, “A complete analysis and a novelsolution for instability in pump controlled a symmetric actuators," Journal of Dynamic Systems, Measurement, and Control, vol. 137, no. 9, 2015.

[16] L. Wang, W. J. Book, and J. D. Huggins, "A hydraulic circuit for single rod cylinders," Journal of dynamic systems, measurement, and control, vol. 134, no. 1, 2012.

[17] L. Wang and W. J. Book, “Using leakage to stabilize a hydraulic circuit for pump controlled actua tors," Journal of Dynamic Systems, Measurement, and Control, vol. 135, no. 6, 2013.

(C) 2020 by the authors; licensee MDPI, Basel, Switzerland. This article is an open access article distribute $\mathrm{d}$ under the terms and conditions of the Creative Commons by Attribution (CC-BY) license (http://creativecommons.org/licenses/by/4.0/). 